\title{
A comparative study of atorvastatin and rosuvastatin on lipid lowering efficacy in hyperlipidemic patients
}

\author{
Samia Haque Tonu, Zesmin Fauzia Dewan, Nargis Akhter and Sajal Krishna Banerjee
}

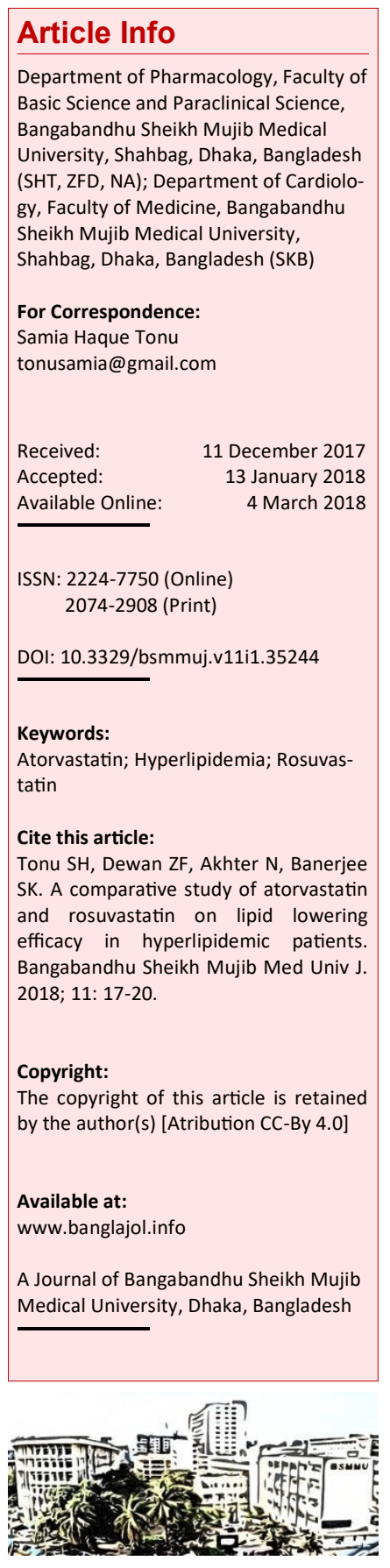

\begin{abstract}
The aim of the present study was to compare the lipid lowering effect of atorvastatin and rosuvastatin in patients $(n=52)$ with hyperlipidemia. Patients were assigned to atorvastatin $10 \mathrm{mg}$ or rosuvastatin $5 \mathrm{mg}$ daily for 8 weeks. The blood was collected at baseline and after intervention to measure the serum lipid profile. The level of serum total cholesterol in both atorvastatin and rosuvastatin groups was significantly reduced after intervention $(p<0.00001$ and $p<0.00001$ respectively) but no statistically significant difference $(p=0.503)$ was observed between the two statin-treated groups. The reduction of serum triglyceride level was also significant $(\mathrm{p}=0.046$ in atorvastatin group and $p=0.0006$ in rosuvastatin group). No significant difference was observed between the two groups $(p=0.312)$. The serum LDL-C level was reduced significantly in both atorvastatin group $(\mathrm{p}<0.00001)$ and rosuvastatin group $(\mathrm{p}<0.00001)$. Again no statistically significant difference $(p=0.749)$ was observed between the two groups. No significant change was observed in the serum HDL level. Intergroup difference was not significant $(p=0.721)$. The present study indicates that both atorvastatin and rosuvastatin improve the lipid profile but no significant change was observed between the two groups.
\end{abstract}

\section{Introduction}

Hyperlipidemia is an abnormal elevation of serum lipid levels in the blood which culminate in the development of atherosclerosis. 1 Atherosclerosis is a chronic disease of arterial wall and may give rise to myocardial infarction, ischemic stroke and peripheral vascular disease as its aftermath.? Globally, one-third of ischemic heart disease is attributable to high cholesterol level, which is estimated to cause 2.6 million death and 29.7 million disabilities. 3 Hydroxymethyl glutaryl coenzyme-A (HMG Co-A) reductase inhibitor drugs (statins) are quite effective in treating dyslipidemia and therefore, are widely used for prevention and treatment of cardiovascular diseases. $\underline{4}$ By reducing the synthesis of mevalonate, the immediate product of HMG-CoA, statins inhibit the synthesis of cholesterol. 5 Several drugs are included within the statin group, among them atorvastatin and now-a-days rosuvastatin is widely used.

The present study was planned to compare the lipid lowering efficacy of the newer emerging and promising statin rosuvastatin with the existing commonly used statin atorvastatin in patients with dyslipidemia so as to guide the present treatment strategies.

\section{Materials and Methods}

An 8-week, randomized, open trial was conducted by recruiting the patients from the Outpatient Department of Cardiology. Eligible patients were randomized to receive once daily dose of $10 \mathrm{mg}$ atorvastatin or $5 \mathrm{mg}$ rosuvastatin for 8 weeks.

The study population comprised 52 hyperlipidemic patients, both male and female, $\underline{6}$ aged 20-75 years. $\underline{7-9}$ Eligibility criteria for randomized treatment included the fasting LDL-C level $>160 \mathrm{mg} / \mathrm{dL}$ and fasting triglyceride level $<400 \mathrm{mg} / \mathrm{dL} . \underline{10}$ Patients were treated by other lipid lowering drugs,, 11 history of smoking, alcohol intake $\underline{12}$ and hypersensitivity on any member of the statin group of drugs, $\underline{11}$ taking anti-inflammatory medications, $\underline{12}$ anti-oxidant vitamins (vitamin A, C, E), $\underline{13}$ anticoagulant or antiplatelet drugs, $\underline{14}$ impaired liver and renal function, $\underline{11}$, $\underline{15}$ having serious infections or terminal illness, $\underline{12}$ pregnant women and nursing mother were not enrolled. $\underline{11}$ Baseline measurements 
included the levels of serum total cholesterol, triglyceride, low-density lipoprotein cholesterol (LDL-C) and high-density lipoprotein cholesterol (HDL-C) with follow-up measurements after 8 weeks. With all aseptic precaution, $5 \mathrm{~mL}$ of blood was collected by venipuncture from the antecubital vein and kept it in $1 \times 5 \mathrm{~mL} \mathrm{~K} \mathrm{~K}_{3}$ EDTA (anticoagulant) containing test tube. The plasma was separated by centrifugation $(3,500 \mathrm{rpm}$ for $10 \mathrm{~min}$ ) and stored at labeled Eppendorf tube by micropipette, then stored at $-20^{\circ} \mathrm{C}$ in a refrigerator until analysis. Drugs were advised to take at night before meal. Regularity of drug intake was ensured over telephone and from the patient's compliance sheet. Patients were asked to report any adverse effect of the medication given during the period of study. Patients was strictly advised to take fat restricted diet.

\section{Statistical analysis}

Data were processed and recorded in the Microsoft Excel Worksheet. The quantitative variables were expressed as mean \pm SD. Differences in mean values between groups were assessed by using the two tailed paired and unpaired student's t-test. The level of significance was set at ' $p$ ' value less than 0.05 .

\section{Results}

Table I shows the baseline demographic characteristic of all hyperlipidemic patients. There were in total 21 males and 31 females. Considering demographic characteristics, there was no significant

\begin{tabular}{|c|c|c|c|}
\hline \multicolumn{4}{|c|}{ Table I } \\
\hline \multicolumn{4}{|c|}{ Demographic characteristics of both groups before intervention } \\
\hline Characteristics & $\begin{array}{l}\text { Atorvastatin } \\
\text { Group } \\
(n=27)\end{array}$ & $\begin{array}{c}\text { Rosuvastatin } \\
\text { Group } \\
(n=25)\end{array}$ & $\mathrm{p}$ value \\
\hline Age (years) & $46.0 \pm 10.5$ & $44.1 \pm 8.3$ & $0.740^{\mathrm{a}}$ \\
\hline Sex & & & $0.005 \phi$ \\
\hline Male & 6 & 15 & $0.005 \phi$ \\
\hline Female & 21 & 10 & $0.005 \phi$ \\
\hline Body weight (kg) & $69.7 \pm 9.5$ & $66.8 \pm 8.7$ & $1.150 \mathrm{a}$ \\
\hline Blood pressure & & & $0.512^{\mathrm{a}}$ \\
\hline Systolic (mmHg) & $131.8 \pm 16.4$ & $135.2 \pm 20.8$ & $0.512^{\mathrm{a}}$ \\
\hline Diastolic (mmHg) & $81.5 \pm 9.9$ & $85.8 \pm 11.7$ & $0.156^{\mathrm{a}}$ \\
\hline Hypertension & 13 & 18 & $0.080 \phi$ \\
\hline Diabetes mellitus & 2 & 2 & $0.936 \phi$ \\
\hline
\end{tabular}

difference between the atorvastatin and rosuvastatin-treated groups.

Before administration of atorvastatin and rosuvastatin, the serum cholesterol level (mean \pm SD) in the respective group was $257.5 \pm 21.8 \mathrm{mg} / \mathrm{dL}$ and 262.5 $\pm 38.7 \mathrm{mg} / \mathrm{dL}$. After 8 weeks of drug administration, the same parameter was changed to $161.6 \pm$ $39.6 \mathrm{mg} / \mathrm{dL}$ in atorvastatin group and $154.6 \pm 35.5$ $\mathrm{mg} / \mathrm{dL}$ in rosuvastatin group (Table II). This change was statistically significant $(p<0.00001$ and $\mathrm{p}<0.00001$ respectively) but after intervention no statistically significant difference was found in between the two groups $(p=0.503$, Table II). The mean decrease (\%) in serum cholesterol in the atorvastatin-treated group was $37.2 \%$ and in rosuvastatin-treated group was $41.1 \%$ (Table II).

At baseline, the serum triglyceride level (mean \pm SD) in atorvastatin and rosuvastatin-treated groups was $199.7 \pm 80.7$ and $198.9 \pm 56.0 \mathrm{mg} / \mathrm{dL}$. After 8 weeks of drug administration, the serum triglyceride level was changed to $165.6 \pm 75.5$ and $145.6 \pm$ $65.0 \mathrm{mg} / \mathrm{dL}$ in atorvastatin and rosuvastatin group respectively (Table II). This change was statistically significant $(p=0.046$ and 0.0006 respectively). No statistical significant difference was found after intervention in between the groups ( $p=0.312$; Table II). The mean decrease (\%) in serum triglyceride in the atorvastatin treated group was $17.1 \%$ and in rosuvastatin treated group was $26.8 \%$ (Table II).

Before administration of atorvastatin and rosuvastatin, the serum LDL-C levels in the respective groups was $178.2 \pm 20.0$ and $181.6 \pm 32.1 \mathrm{mg} / \mathrm{dL}$. After 8 weeks of drug administration, the same parameter was changed to $89.1 \pm 35.2 \mathrm{mg} / \mathrm{dL}$ in atorvastatin group and $85.9 \pm 35.5 \mathrm{mg} / \mathrm{dL}$ in rosuvastatin group respectively (Table II). This change was statistically significant $(p<0.00001$ and 0.00001 respectively) but again no significant difference was found between the groups after intervention $(\mathrm{p}=0.749$; Table II). The mean decrease (\%) in serum LDL-C in the atorvastatin treated group was $50.0 \%$ and in rosuvastatin treated group was $52.7 \%$ (Table II).

At baseline, the serum HDL-C level (mean \pm SD) in atorvastatin and rosuvastatin groups was $39.4 \pm 9.6$ and $41.1 \pm 7.8 \mathrm{mg} / \mathrm{dL}$. After 8 weeks of drug administration the serum HDL-C level was $39.4 \pm$ 11.5 and $40.4 \pm 9.1 \mathrm{mg} / \mathrm{dL}$ in atorvastatin and rosuvastatin group respectively (Table II). But this change was not statistically significant $(p=0.990$ and 0.696 respectively). Again no significant difference was found after intervention in between the groups $(\mathrm{p}=0.721$; Table II). The mean decrease $(\%)$ in serum HDL-C in the atorvastatin-treated group was $0.1 \%$ and in rosuvastatin-treated group was $1.8 \%$ (Table II).

Both atorvastatin and rosuvastatin were well tolerated by patients of the present study. Two 


\begin{tabular}{|c|c|c|c|c|c|c|c|c|c|c|}
\hline \multicolumn{11}{|c|}{ Table II } \\
\hline \multicolumn{11}{|c|}{ Effect on serum lipid profile } \\
\hline \multirow[t]{2}{*}{$\begin{array}{l}\text { Variables } \\
(\mathrm{mg} / \mathrm{dL})\end{array}$} & \multicolumn{4}{|c|}{$\begin{array}{l}\text { Atorvastatin group } \\
\qquad(\mathrm{n}=27)\end{array}$} & \multicolumn{4}{|c|}{$\begin{array}{l}\text { Rosuvastatin group } \\
\qquad(\mathrm{n}=25)\end{array}$} & \multirow[t]{2}{*}{$\begin{array}{l}{ }^{£} \mathrm{p} \\
\text { value }\end{array}$} & \multirow[t]{2}{*}{$\begin{array}{l}{ }^{b p} \\
\text { value }\end{array}$} \\
\hline & Before & After & ${ }^{a} p$ value & $\begin{array}{c}\% \\
\text { Change }\end{array}$ & Before & After & $\mathrm{p}^{\mathrm{a}}$ value & $\begin{array}{c}\% \\
\text { Change }\end{array}$ & & \\
\hline $\begin{array}{l}\text { Total choles- } \\
\text { terol }\end{array}$ & $257.5 \pm 21.8$ & $161.6 \pm 39.6$ & $<0.00001$ & $\downarrow 37.2$ & $262.5 \pm 38.7$ & $154.6 \pm 35.5$ & $<0.00001$ & $\downarrow 41.1$ & 0.566 & 0.503 \\
\hline Triglyceride & $199.7 \pm 80.7 \mathrm{a}$ & $165.6 \pm 75.5$ & 0.046 & $\downarrow 17.1$ & $198.9 \pm 56.0$ & $145.6 \pm 65.0$ & 0.0006 & $\downarrow 26.8$ & 0.966 & 0.312 \\
\hline LDL-C & $178.2 \pm 20.0$ & $89.1 \pm 35.1$ & $<0.00001$ & $\downarrow 50.0$ & $181.6 \pm 32.1$ & $85.9 \pm 35.5$ & $<0.00001$ & $\downarrow 52.7$ & 0.645 & 0.749 \\
\hline HDL-C & $39.4 \pm 9.6$ & $39.4 \pm 11.5$ & 0.990 & $\downarrow 0.1$ & $41.1 \pm 7.8$ & $40.4 \pm 9.1$ & 0.696 & $\downarrow 1.8$ & 0.478 & 0.721 \\
\hline
\end{tabular}

patients in the atorvastatin group complained of abdominal discomfort and headache and one patient in the rosuvastatin group complained of constipation. No serious adverse effect was seen in both the groups that needed dose adjustment or withdrawal of the drug.

\section{Discussion}

Data from the VOYAGER meta-analysis suggested that each rosuvastatin dose is equivalent to dose 3 3.5 time higher for atorvastatin regarding reduction of LDL-C. $\underline{16}$ This would indicates that $5 \mathrm{mg}$ rosuvastatin equivalent to $15-20 \mathrm{mg}$ of atorvastatin.

The present study has observed the beneficial effects of atorvastatin and rosuvastatin on serum lipid profile. Both of them significantly reduced the serum total cholesterol, triglyceride and LDL-C levels significantly after drug treatment, which was according to previous research findings. $11,17,18$ A 12week study shows with both rosuvastatin $(5 \mathrm{mg})$ and rosuvastatin $(10 \mathrm{mg})$ significantly reduced the total cholesterol and LDL-C compared with atorvastatin $(10 \mathrm{mg})$-treated patients. $\underline{19}$ Another study of 8-week treatment with rosuvastatin (10 $\mathrm{mg}$ ) significantly decreased the triglyceride and LDL-C to a better extent as compared to that of atorvastatin $(10 \mathrm{mg}) \cdot \underline{6}$ This would suggests that 5 $\mathrm{mg}$ dose of rosuvastatin may be inadequate for the significant improvement of lipid profile compared to $10 \mathrm{mg}$ atorvastatin. In present study, no significant elevations were noticed regarding HDL$C$ levels. Inspite, small reduction of HDL-C level was observed in both the groups. This bears resemblance with one previous study using atorvastatin and rosuvastatin, which shows mild reduction of serum HDL-C level after 4 weeks of treatment.11 A similar study has demonstrated the decreased HDL-C level in the initial 6 weeks followed by increased level of HDL-C after 16 weeks of intervention. $\underline{20}$ Although no clear explanation is available at the moment regarding this decrease in HDL-C level of the present study, it could be expected that perhaps a longer time period than 8 weeks would have been required to effectively demonstrate the effects of the statins upon serum HDL-C level.

In this trial, both atorvastatin and rosuvastatin were quite effective in reducing serum LDL-C level in hyperlipidemic patients. When the serum lipid lowering effects were assessed by percentage, rosuvastatin demonstrated a higher percentage of ameliorating changes compared to those of atorvastatin. Both drugs exhibited a similar safety profile. Therefore, rosuvastatin constitutes a better therapeutic option compared to atorvastatin for reducing the serum LDL-C level in patients with hyperlipidemia.

\section{Conclusion}

Both atorvastatin and rosuvastatin have effectively improved the lipid profile in hyperlipidemic patients. No significant change is observed between the two groups, although considering percentage changes of effects produce by the rosuvastatin appears better.

\section{Ethical Issue}

This protocol was approved by the Institution Review Board of BSMMU (No. BSMMU/2016/8307 dated 13-08-2016). This study was also registered in ClinicalTrial.gov and study ID number wasNCT02979704. The informed written consent was obtained from all the participants before starting the study. 


\section{References}

1. Grundy SM. Pathogenesis of hyperlipoproteinemia. J Lipid Res. 1984; 25: 1611-18.

2. Herrington W, Lacey B, Sherliker P, Armitage J, Lewington $\mathrm{S}$. Epidemiology of atherosclerosis and the potential to reduce the global burden of atherothrombotic disease. Circ Res. 2016; 118: 53546.

3. World Health Organization (WHO), 2017, Global Health Observatory (GHO) data. World Health Organization (WHO), Geneva, Switzerland. Available at: http://www.who.int/gho/ncd/ risk_factors/cholesterol_text/en/ [Accessed on 17th July 2017]

4. Sugiyama M, Ohashi M, Takase H, Sato K, Ueda $\mathrm{R}$, Dohi Y. Effects of atorvastatin on inflammation and oxidative stress. Heart Vessels. 2005; 20: 13336.

5. Rikitake Y, Liao JK. Rho GTPases, statins and nitric oxide. Circ Res. 2005; 97: 1232-35.

6. Anand IS, Modhwadia SS, Sharma KH. Effect of atorvastatin and rosuvastatin on inflammatory markers in hyperlipidemic patients. IJPRBS. 2014; 3: 97-107.

7. Jialal L, Stein D, Balis D, Grundy SM, Huet BA, Devaraj S. Effect of hydroxymethyl glutaryl coenzyme: A reductase inhibitor therapy on high sensitive C-reactive protein levels. Circulation 2001; 103: 1933-35.

8. Yoshino G, Tanaka M, Nakano S, Matsumoto T, Kojima M, Murakami E, Morita T. Effect of rosuvastatin on concentrations of plasma lipids, urine and plasma oxidative stress markers and plasma high-sensitivity C-reactive protein in hypercholesterolemic patients with and without type 2 diabetes mellitus: A 12-week, open-label, pilot study. Curr Ther Res Clin Exp. 2009; 70: 439-48.

9. Kurabayashi M, Yamazaki T, SUBARU study group. Superior benefit of aggressive lipid-lowering therapy for high-risk patients using statins: The SUBARU study: More hypercholesterolemic patients achieve Japan atherosclerosis society LDL -C goals with rosuvastatin therapy than with atorvastatin therapy. J Atheroscler Thromb. 2008; 15: 314-23

10. National Cholesterol Education Program. Adult treatment panel III guidelines at-a-glance quick desk reference, 2001. Available at: https:// www.nhlbi.nih.gov/files/docs/guidelines/ atglance.pdf [Accessed on 16 th July 2017]

11. Khurana S, Gupta S, Bhalla H, Nandwani S,
Gupta V. Comparison of anti-inflammatory effect of atorvastatin with rosuvastatin in patients of acute coronary syndrome. J Pharmacol Pharmacother. $2015 ; 6$ : 130-35.

12. Marketou ME, Zacharis EA, Nikitovic D, Ganotakis ES, Parthenakis FI, Maliaraki N, Panos E, Vardas PE. Early effects of simvastatin versus atorvastatin on oxidative stress and proinflammatory cytokines in hyperlipidemic subjects. Angiology 2006; 57: 211-18.

13. Li J, Sun YM, Wang LF, Li ZQ, Pan W, Cao HY. Comparison of effects of simvastatin versus atorvastatin on oxidative stress in patients with coronary heart disease. Clin Cardiol. 2010; 33: 222-27.

14. Joukhadar C, Klein N, Prinz M, Schrolnberger C, Vukovich T, Wolzt M, Schmetterer L, Dorner GT. Similar effects of atorvastatin, simvastatin and pravastatin on thrombogenic and inflammatory parameters in patients with hypercholesterolemia. Thromb Haemost. 2000; 85: 47-51.

15. Hadi NR, Abdelhussein MA, Alhamami OMO, Rudha ARM, Sabah E. Anti-oxidant effect of atorvastatin in type 2 diabetic patients. Pharmacol Pharm. 2010; 1: 53-59.

16. Karlson BW, Palmer MK, Nicholls SJ, Lundman P, Barter PJ. Doses of rosuvastatin, atorvastatin and simvastatin that induce equal reductions in LDL$C$ and non-HDL-C: Results from the VOYAGER meta-analysis. Eur J Prev Cardiol. 2016; 23: 744-47.

17. Adsule SM, Baig MS, Gade PR, Khandelwal PN. A comparative evaluation of safety and efficacy of rosuvastatin, simvastatin and atorvastatin in patients of type 2 diabetes mellitus with dyslipidemia. Int J Diabetes Dev Ctries. 2009; 29: 74-79.

18. Kilit C, Kocak FE, Kilit TP. Comparison of the effects of high-dose atorvastatin and high-dose rosuvastatin on oxidative stress in patients with acute myocardial infarction: A pilot study. Turk Kardiyol Dern Ars. 2017; 45: 235-43.

19. Olsson AG, Istad H, Luurila O, Ose L, Stender S, Tuomilehto J, Wiklund O, Southworth H, Pears J, Wilpshaar JW. Effects of rosuvastatin and atorvastatin compared over 52 weeks of treatment in patients with hypercholesterolemia. Am Heart J. 2002; 144: 1044-51.

20. Schwartz GG, Olsson AG, Ezekowitz MD, Ganz P, Oliver MF, Waters D, Zeiher A, Chaitman BR, Leslie S, Stern T. Myocardial Ischemia Reduction with Aggressive Cholesterol Lowering (MIRACL) study investigators. Effects of atorvastatin on early recurrent ischemic events in acute coronary syndromes: The MIRACL study: A randomized controlled trial. JAMA. 2001; 285: 1711-18. 